\title{
PARTICLES IN \\ GASES AND LIQUIDS 3
}

Detection, Characterization, and Control 


\section{PARTICLES IN GASES AND LIQUIDS 3}

Detection, Characterization, and Control

Edited by

K. L. Mittal

Skill Dynamics, an IBM Company

Thornwood, New York 


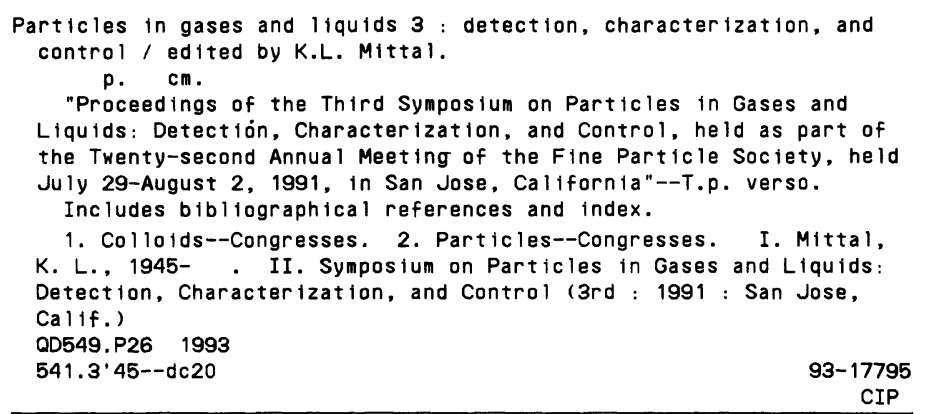

Proceedings of the Third Symposium on Particles in Gases and Liquids: Detection, Characterization, and Control, held as part of the Twenty-Second Annual Meeting of the Fine Particle Society, held July 29-August 2, 1991, in San Jose, California

\section{ISBN 978-1-4899-1189-6 \\ ISBN 978-1-4899-1187-2 (eBook) \\ DOI 10.1007/978-1-4899-1187-2}

(C) Springer Science+Business Media New York 1993

Originally published by Plenum Press, New York in 1993

Softcover reprint of the hardcover 1st edition 1993

\section{All rights reserved}

No part of this book may be reproduced, stored in a retrieval system, or transmitted in any form or by any means, electronic, mechanical, photocopying, microfilming, recording, or otherwise, without written permission from the Publisher 
This book documents the proceedings of the Third Symposium on Particles in Gases and Liquids: Detection, Characterization and Control held as a part of the 22nd Annual Meeting of the Fine Particle Society in San Jose, California, July 29-August 2, 1991. This series of symposia was initiated in 1987 in light of the growing importance to eliminate particles from process gases and liquids.

As pointed out in the Preface to antecedent volumes in this series that particles in process gases and liquids could cause significant yield losses in precision manufacturing and concomitantly there has been heightened interest in understanding the behavior of particles in gases and liquids and devising ways to eliminate, or at least reduce substantially, these particles. The concern about particles in gases and liquids has been there for qui.te some time in the microelectronics arena, but there are other areas also where particles are of significant concern, e.g. in operation theatres in hospitals, food and beverage industry, and pharmaceutical manufacturing.

This symposium basically had the same objectives as its predecessors, but to provide an update on the $R \& D$ activity taking place in the arena of particle detection, characterization and control. The printed program comprised a total of 28 papers dealing with variegated aspects of particles in gases and liquids. There were brisk and lively discussions and the attendees offered many positive comments, which goes to show that it was a well-received and needed symposium.

Before commenting on the present volume, it should be recorded that all manuscripts were rigorously peer reviewed, and most of these were substantially revised before inclusion in this volume. So this volume comprises a set of papers which have passed peer scrutiny, and not just a bunch of "as-received" manuscripts.

The present volume contains 18 papers and the topics covered include: aerosol transport in turbulent flows; deposition of submicrometer particles on surfaces; testing philosophy for UHP gas handling components; particle measurement in process gas stream; filter and filtration efficiency; design of cleanroom airflows using CFD analysis; cosmetics as a potential source of particulate contamination in the cleanroom; particle release from cleanroom operators; particle contamination in plasma processing; characterization and monitoring of particles in pharmaceutical manufacturing; monitoring particles in liquids; and Marangoni drying.

I certainly hope that this and earlier volumes ${ }^{1,2}$ in this series will serve as a fountain of information on detection, characterization and control of particles in gases and liquids. 
Acknowledgments: First, thanks are due to the Fine Particle Society for sponsoring this event. I am thankful to the appropriate management of IBM Corporation for permitting me to organize this symposium and to edit this volume. The reviewers provided many useful comments and I extend my special thanks to them for their time and efforts. Also I would like to express my appreciation to my wife, Usha, for providing help and support in more ways than one. Finally, this book would not have seen the light of day without the support, interest and contribution of the authors; and I extend my appreciation and thanks to them.

K.L. Mittal

Skill Dynamics, an IBM Company 500 Columbus Ave.

Thornwood, NY 10594

\section{REFERENCES}

1. K.L. Mittal, Editor, Particles in Gases and Liquids 1: Detection, Characterization and Control, Plenum Press, New York, 1989.

2. K.L. Mittal, editor, Particles in Gases and Liquids 2: Detection, Characterization and Control, Plenum Press, New York, 1990. 
CONTENTS

Overview of Digital Simulation Procedures for Aerosols

Transport in Turbulent Flows

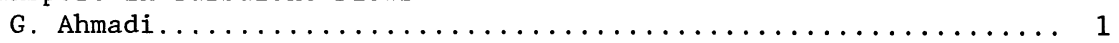

Deposition of Submicron Particles on Surfaces, Part I:

Electrostatic Effect

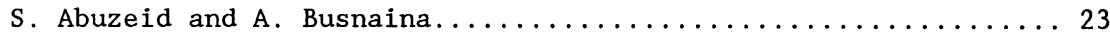

Deposition of Submicron Particles on Surfaces, Part II:

Turbulence Effect

S. Abuzeid and A. Busnaina....................... 35

The Influence of Solution Properties on the Deposition of

Particles from Liquid Media onto Silicon Wafer Surfaces

D.J. Riley and R.G. Carbonell..................... 51

Thermophoretically Enhanced Deposition of Sub-Micrometer

Particles from a Hot Turbulent Gas

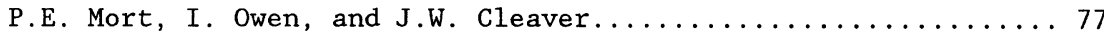

Statistics of Continuous Particulate Measurement in Process

Gas Streams

M.L. Malczewski............................. 87

Testing Philosophy and Methodology for UHP Gas Handling

Components

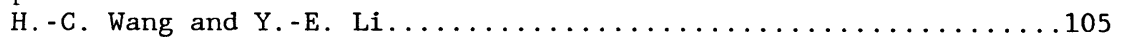

A Two-Stage Virtual Impactor for Continuous Concentration of

Particles in an Aerosol

M.P. Sinha.

Evaluation of the API Aerosizer Mach 2 Particle Sizer

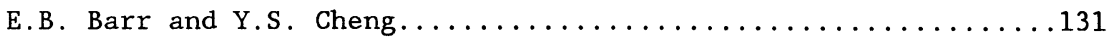

A Triboelectrically Charged Granular Filter with High

Filtration Efficiency

M.K. Mazumder, K.B. Tennal, and S. Gao................... 141

Reduction of Aerosolized Lubricant Contamination in the Airstream of Disk Drives by Proper Ball Bearing Seal Designs

W. Prater, M. Dominguez, R. Giger, and G. Stone.............. 151

Design of Cleanroom Airflows for Particle Control Using CFD Analysis: Case Studies

$\mathrm{K}$. Goldstein and J. Divelbiss. 
Cosmetics as a Potential Source of Particulate Contamination

in the Clean Room

L.R. Hauenstein.................................189

Factors Affecting the Number of Airborne Particles Released

from Clean Room Operators

C. Baczkowski..................................203

Scientific and Technological Issues Pertaining to Particle

Contamination in Plasma Processing

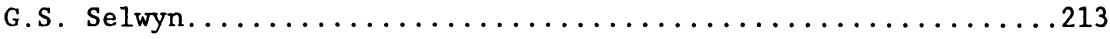

Enumeration, Characterization, and Monitoring of Particles in

Pharmaceutical Manufacturing

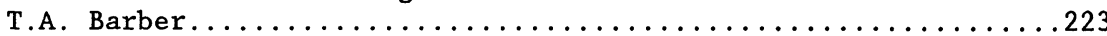

Use of A Modified Particle Recognition and Characterization (PRC)

Technique to Monitor Cleaning Fluids in HDA Fabrication

E. Ackerman and R. Adams........................... 257

U1traclean Marangoni Drying

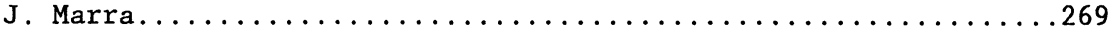

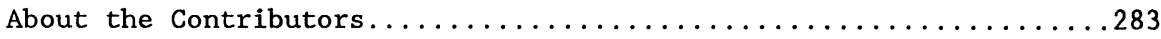

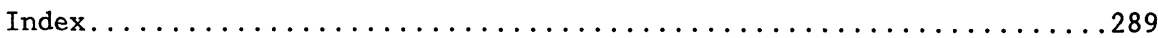

